\title{
Konaklama İşletmelerinde Kurumsal Sosyal Sorumluluk Algısının İş Doyumu Üzerine Etkisi
}

\author{
The Impact of Corporate Social Responsibility on Job Satisfaction in Hotels
}

\author{
Nilgün $\mathrm{AVCl}^{1}$, İbrahim AKDEMiR ${ }^{2}$
}

\begin{abstract}
ÖZET
Bu çalışmada, konaklama işletmelerinin kurumsal sosyal sorumluluk algılarının çalışanların iş doyumu üzerindeki etkileri araştırılmıştır. Çalışmada kurumsal sosyal sorumluluk; etik, gönüllülük ve ekonomik sosyal sorumluluk olarak üç boyutta ele alınmıştır. Araştırma yöntemi olarak alan araştırma yöntemi kullanılmış, yapılandırılmış anket tekniği ile veriler Çeşme'de faaliyet gösteren 4 ve 5 yıldızlı oteller, butik oteller ile tatil köylerinde çalışanlardan toplanmıştır. Toplanan verilere SPSS 16 paket programı kullanılarak, faktör analizi ve regresyon analizi uygulanmıştır. Çalışmanın bulguları,kurumsal sosyal sorumluluğun, etik ve ekonomik sosyal sorumluluk boyutlarınıniş doyumunu olumlu yönde etkilediğini göstermektedir.Bulgular, KSS uygulamalarının, işletmelerin işgörenleri ile ilişkilerinde olumlu etkisinin olabileceğini göstermektedir. Çalışmanın sonuçları, konaklama işletmeleri yöneticileri için pratikte, kurumsal sosyal sorumluluk ve iş doyumu stratejileri geliştirirken yararlı olabilir.
\end{abstract}

Anahtar Kelimeler: İs doyumu, kurumsal sosyal sorumluluk, konaklama işletmeleri.

\section{GíRiş}

Kurumsal sosyal sorumluluk (KSS) günümüz işletmecilik alanında önemli bir araştırma konusu haline gelmiştir. KSS'nin, tüketicilerin marka tercihi ve marka sadakatini etkileyen marka farkındalığı (Mohr ve Webb, 2005), mevcut ve potansiyel çalışanların kuruluşa karşı olumlu algıları ve iş ortaklarının olumlu tutumları (Rupp ve diğerleri, 2006; Lee ve diğerleri, 2011) gibi yararları, işletmelere KSS'yi işletmeciliğin bir parçası haline getirmelerini teşvik etmektedir.Ekonomik olduğu gibi, aynı zamanda sosyal birimler olantoplumla iç içe faaliyet gösteren işletmeler, toplumun beklentileri ile paralel olarak yeni sorumluluklar da yüklenmeye başlamışlardır. Günümüzde işletmelerin her türlü faaliyetlerinde; tüm paydaşlarına olacak etkilerini göz önünde tutması, etik ve sorumlu davranması beklenmektedir (Valentine ve Fleishman, 2008). Toplumsal dönüşüm aracı olarak görülen işletmelerin değişim faaliyetleri; sağlık, doğa ve ekonomik gelişme gibi konularda, küresel yada yerel ölçekte toplumun refahını arttıran girişimlerdir (Bies vd., 2007).

\begin{abstract}
The main objective of this research is to analyze the impact of corporate social responsibility on job satisfaction in hotels. Dimensions of corporate social responsibility used in the study include economic, philanthropic, and ethical aspects. A total of 229 employees in 7 hotels in Çesme area constitued the sample of this study. Data is collected through a structured questionnaire. After testing for the basic aspects of reliability and validity, regression and factor analyses are used to test the hypotheses of the study. The findings of the study show that ethical and economic dimensions of CSR have a positive effect on job satisfaction. In building of these findings, it is argued that CSR performance can be an effective way for companies to maintain a positive relationship with their employees and this study provides practical implications for hotel managers when implementing CSR and JS strategies.
\end{abstract}

Keywords: Job satisfaction, corporate social responsibility, hotels.

İşletmelerin ticaretin yanı sıra ekonomik, toplumsal ve çevre ile ilgili sorumluluk taşımaları görüşüturizm işletmelerini de içine almaktadır. Turizm işletmeleri sosyal sorumluluk uygulamaları ile sürdürülebilir gelişim gösterebilmektedirler (Henderson, 2007; Sloan, Legrand ve Chen, 2009; Tsai, Tsang ve Cheng, 2012). Küreselleşme, iklim değişikliği, demografik değişiklikler, yoksulluk nedeniyle, hızla değişen turizm pazarında işletmeler fark yaratan sürdürülebilir ürünlerle rekabet edebilmektedirler (Golja ve Nizic, 2010:107). İşletmelerin, müşterileri, hisse sahipleri ve işgörenleri gibi birçok paydaşının beklentilerini karşılama çabasında, KSS faaliyetlerinin her bir paydaş için algısını anlaması faydalı olacaktır. KSS ile ilgili çalışmalarda, KSS'nin ekonomik çıtılara (Margolis ve Walsh, 2003) ve pazarlama tekniklerine (Martens ve Arkidge, 2006) etkileri üzerinde durulduğu görülmektedir. Son dönemde ise, çalışmalar çok yönlü sosyal faydalara yönelmiştir (Valentine ve Fleishman, 2008). Kurumsal sosyal sorumluluk konusundaki farkındalığın artmaSı, işletmelerin sorumlu davranışlarının işgörenlerin

\footnotetext{
${ }^{1}$ Yrd. Doç. Dr., Ege Üniversitesi, Çeşme Turizm ve Otelcilik Yüksekokulu,Konaklama İşletmeciliği Bölümü, nilgun.avci@ege.edu.tr

${ }^{2}$ Ege Üniversitesi, Çeşme Turizm ve Otelcilik Yüksekokulu, Konaklama İşletmeciliği Bölümü, ibrahim_ak_demir@hotmail.com
} 
refahındaki etkisini sorgulanmasını da sağlamaktadır (Yamak 2007). Rodrigo ve Arenas (2008) buna rağmen kurumsal sosyal sorumluluk yazınında; işgörenlerin, diğer paydaşlar ile karşılaştırıldığında daha az dikkate alındığını belirtmişlerdir. Az sayıda çalışmada KSS'nin işgörenler üzerindeki etkisinin(Rupp ve diğerleri, 2006; Brammer, Millington ve Rayton, 2007; Özdemir, 2007; Valentine ve Fleischman, 2008; Çalışkan ve Ünüsan, 2011; Hansen ve diğerleri, 2011; Lee ve diğerleri, 2011)araştıııldığı görülmektedir. Tuzzolino ve Armandi'nin (1981) çalışmalarının bulgularından hareketle, işletmelerin ana paydaşları olan işgörenlerin (Tripathy ve Rath 2011) kurumsal sosyal sorumlulukla ilgili beklentileri karşılandığında, işgörenlerin iş tutumlarında gelişim, verimliliklerinde artış ve işgören devrinde düşme beklenebileceğini belirtmişlerdir.

İnsan kaynakları yazını, örgütlerde işgörenin gücüne (Claydon ve Doyle 1996) vurgu yapmaktadır. Benzer şekilde Greenwood (2007) çalışmasında, en başta gelen paydaşın işgörenler olduğunu belirtmektedir. Bu nedenle, bu çalışmada işgörenlere yoğunlaşılmış, KSS'nin işletme içi paydaşlara yani işgörenlere etkilerinin araştırılması amaçlanmıştır. Çalışmanın amacl, konaklama işletmelerinde KSS'nin işgörenlerin iş doyumu üzerindeki etkisini belirlemektir. İşdoyumu, işgören temelli araştırmalarda önemli bir değişken olarak kabul edilmektedir (Spector, 1997). İşörenlerin konaklama işletmeleri performansında ve finansal başarısında anahtar rol oynadığı(Tütüncü ve Çiçek, 2000) ve insan yaşamındaki önemi göz önünde tutulursa, kurumsal sosyal sorumluluk ile iş doyumu arasındaki ilişkiyi ortaya koymak önemli hale gelmektedir. Bu çalışma ile yazına katkıda bulunmak amaçlandığı gibi, çalışmanın konaklama işletmeleriyöneticilerine pratikte faydalı olacağı da düşünülmektedir.

\section{YAZIN TARAMASI}

\subsection{Kurumsal Sosyal Sorumluluk}

Yazına göz atıldığında Türkiye'de ve dünyada kurumsal sosyal sorumluluğa verilen önemin artmakta olduğu görülmektedir. Tripathy ve Rath (2011) günümüzde işletmelerin büyük çoğunluğununyalnızca finansal hedeflere ulaşmaktan öte sosyal hesap verebilirliğin farkına vardıklarını belirtmektedirler.Birçok yazar kurumsal sosyal sorumlulukla ilgili akademik çalışmaların Bowen'ın (1953) "Social Responsibilities of Businessman" yayını ile başladığını öne sürmektedir (Örn:Inoue ve Lee, 2010; Akdoğan ve Bay, 2012; Lis, 2012). Bowen (1953) sosyal sorumluluğu; işletmelerin gerek kendi amaçlarına, gerekse toplumsal beklentilere uygun politikalar belirleme ve uygulama, karar verme ve faaliyetleri yerine getirme ile toplumsal yaşamı iyileştirmeye ilişkin yükümlülüklerinin bütünü olarak tanımlamıştır. Kurumsal sosyal sorumluluk, işletmelerin tüketicilerine, işgörenlerine, hissedarlarına, topluma ve çevreye etkisi olan faaliyetlerinin sorumluluğunu almasını içeren bir kavramdır (Tripathy ve Rath, 2011). Kurumsal sosyal sorumluluk şirketlerin toplum ile yasal zorunlulukların ötesinde kurdukları ilişki ve topluma katkıları olarak görülebilir (McWilliams ve Siegel, 2001). Yamak (2009) KSS'yi şirketlerin sosyal, çevresel, ekonomik ve etik alanlarda sosyal paydaşların beklentilerine duyarlılık göstermeleri ve söz konusu kavramları yönetmeleri olarak tarif etmektedir. KSS kavramı üzerine birçok farklı bakış açısı ve tanımı bulunduğu görülmektedir. Bu da farklı paydaşlara dayanarak tanımlama yapıldığından kaynaklandığı gibi, Midttun'e (2007) göre ulusal, kültürel, sosyal durum farklılıkları ve sosyal sorumluluklardaki çeşitlilikler de bu karışıklığa neden olmaktadır. Kurumsal sosyal sorumluluklar ekonomik, yasal, etik ve gönüllü sorumluluklar olarak ele alınmaktadır (Carroll, 1991). Ekonomik sorumluluklar, işletmenin kar ederek yaşamını sürdürme sorumluluğunu içermektedir. Yasal sorumluluklar, işletmenin faaliyetlerini sürdürürken yasalara uyma sorumluluğunu içerirken, etik sorumluluklar, yasalarla belirtilmemesine karşın toplum tarafından beklenilen kurallara uyma sorumluluğunu taşımaktadır. Gönüllü sorumluluklar ise işletmelerin gerek iç gerekse dış sosyal paydaşlarına katkı da bulunmaları ve yaşam kalitesini iyileştirme çabalarıdır (Carroll, 1991).

Birçok çalışmada, KSS faaliyetlerinin işletmelere rekabet avantajı sağladığına (Carroll ve Hatfıeld, 1985; Brammer ve Millington, 2005; Mohr ve Webb, 2005) vurgu yapılırken, Kemper ve Martin (2010) bu avantajın dünyada yaşanan krizle birlikte giderek azaldığını belirtmektedirler.Kurumsal sosyal sorumluluğun müşteri tatmini arttırdığını ortaya koyan birçok çalışma (Brown ve Dacin, 1997; Sen ve Bhattacharya, 2001; Mohr ve Webb, 2005; Luo ve Bhattacharya, 2006; Kim, Kang ve Matilla, 2012) bulunmaktadır.

Diğer sektörlerdeki işletmelerin kurumsal sosyal sorumluluğa olan yoğun ilgisiyleberaberturizm sektöründe de bu ilginin arttığı görülmektedir (Kang; Lee ve Huh, 2010).Turizm sektörünün öncü işletmelerinden, Hilton, Starwood ve Choise Hotels KSS raporu yayınlamaktadırlar (Kang; Lee ve Huh, 2010).Garay ve Font (2012) konaklama işletmelerinin çevreyi ve kişisel değerleri korumak için sosyal sorumluluk faaliyetlerine katıldıklarını belirtmişlerdir.Günümüz turistik tüketicileri, değerlerdeki değişimler, iklim değişikliği, ekonomik kriz gibi sorunlara karşı daha hassas olmalarının yanında, etik tüketim konusunda da duyarlı- 
dırlar (Rudez, 2010: 104). Turizm işletmelerinde bu beklentileri karşılamadakurumsal sosyal sorumluluk olumlu rol oynayabildiği gibi, sürdürülebilir turizm için de önemli bir yere sahiptir (Henderson, 2007; Sloan, Legrand ve Chen, 2009; Golja ve Nizic, 2010; Tsai, Tsang ve Cheng, 2012).Toplumsal bilince sahip, sosyal sorumluluk faaliyetlerini önemseyen turistleri tatmin etmek için, turizm işletmeleri kurumsal sosyal sorumluluklarını yerine getirmeye çalışmaktadırlar (Inoue ve Lee, 2011).Turizm işletmelerinde KSS uygulamalarını araştıran çalışmalar (Henderson, 2007; Pelit, Keleş ve Çakır, 2009; Golja ve Nizic, 2010; Font vd., 2012; Garay ve Font, 2012) incelendiğinde, turizm işletmelerinde KSS uygulamalarının yeterli olmadığı görülmektedir. Kim, Kang ve Mattila (2012) kurumsal sosyal sorumluluğun turizm işletmelerindeki öneminin vurgulanmasına karşın,sınırlı sayıda ampirik çalışmanın yapıldığınıbelirtmektedirler.Kurumsal sosyal sorumluluğun turizm işletmelerinin karlılığında (Lee ve Park, 2009; Inoue ve Lee, 2010; Kang vd., 2010; Grosbois, 2012; Tsai vd., 2012), müşteri memnuniyetindeolumlu etkisini (Lee ve Heo, 2009; Rudez, 2010; Kim, Kang ve Mattila, 2012)araştıran çalışmalar bulunmasına rağmen, az sayıdaki çalışmada (Çalış̧an ve Ünüsan, 2011; Lee vd., 2011) KSS'nin iş doyumu üzerindeki etkisi araştırılmıştır.

Hissedarlara, müşterilere yönelik çok sayıda çaIışma yapılmasına karşın, kurumsal sosyal sorumluluğun işletme içi paydaşlara etkisinin ihmal edildiği fikri birçok yazarca paylaşılmaktadır (Larson vd.,2008; Hansen vd., 2011; Kim vd., 2011). Son dönemlerde kurumsal sosyal sorumluluğun işgörenler üzerine etkisine yönetim yazınında artan bir ilgi olduğu (Berger vd., 2006; Rupp vd., 2006; Brammer vd., 2007; Collier ve Esteban, 2007; Larson vd., 2008; Rodrigo ve Arenas, 2008; Kim vd., 2010; Lee vd., 2011) görülmektedir. Kurumsal sosyal sorumluluğun satış personelinin performansı (Larson vd., 2008), işgörenlerin bağlılığı (Küskü ve Erçek, 2000; Küskü ve Zarkada-Fraser, 2004; Rupp vd., 2006; Brammer vd., 2007; Özdemir, 2007; Turker, 2009; Boddy vd., 2010), işgören güveni (Hansen vd., 2011; Lee vd., 2012), örgütsel vatandaşlık (Özdemir, 2007; Kim vd., 2010), iş doyumu (Valentine ve Fleisman, 2008; Tamm, Eamets ve Mötsmees, 2010) üzerine olumlu etkileri, araştırmalarla ortaya konmuştur.

\subsection{Kurumsal Sosyal Sorumluluk ve İş Doyumu}

İş doyumu örgütsel davranış bilim dalında en çok araştırılan kavramlardan biridir.Locke (1976) iş doyumunu "iş yada iş deneyimleri ile ilgili tatmin edici yada olumlu duygular" olarak tanımlamaktadır.Örgütsel davranış yazını, iş doyumunun birçok değişkenle olumlu ilişkilerinin olduğunu göstermektedir. Örneğin, iş doyumunun, işgören devir hızı (Tett ve Meyer,
1993; Lambert vd., 2001), yüksek iş performansı (Judge vd., 2001), müşteri tatmini (Homburg ve Stock, 2004) ve işgören bağlılığındaki (Tett ve Meyer, 1993; Namasivayam ve Zhao, 2007) olumlu etkileri üzerine çalışılmıştır.Arnett ve diğerlerinin (2002) çalışmaları, müşteri memnuniyetinin, iş doyumu yüksek işgörenlerin sunduğu hizmetle bağlantılı olduğunu göstermektedir. Müşteri ile işgören temasının yoğun ve etkileşim kalitesinin müşterinin deneyimlerinde önemli etkisi nedeniyle, özellikle hizmet sektöründe, iş doyumunun önemli rolü olduğu vurgulanmaktadır (Leiter vd., 1998; Gil, Berenguer ve Cervera, 2008). Bu nedenle geleceği düşünen birçok işletme, işgörenlerinin doyumunu artıracak sistemler için arayışlarına devam etmektedirler (Lee vd., 2011).

Valentine ve Fleischman'ın (2008) çalışmaları kurumsal sosyal sorumluluğun etik programlar ileiş doyumu arasında aracılık rolünün olduğunu göstermektedir.Tamm,Eamets ve Mötsmees(2010) Estonya, Litvanya ve Letonya'da yürüttükleri çalışmada, KSS uygulamalarının iş doyumunda olumlu etkilerinin olduğunu belirlemişlerdir. Çalışmanın sonuçlarına göre, KSS faaliyetleri gerçekleştiren işletmelerin işgörenlerinin, iş doyumunun çalışma koşulları, sosyal ilişkiler, kariyer fırsatları, denetimve ücret boyutları yüksek çıkmıştır. Küskü ve Erçek'in (2000) çalışmalarında vatandaş kuruluş davranışlarının örgütsel bağlılık aracılığı ile iş doyumunu etkilediği belirlenmiştir. Özdemir (2007: 156) işgörenlerin KSS algısının örgütsel özdeşleşme, örgütsel bağlılık ve iş doyumuna etkisini araştırdığı doktora tezinde, kurumsal sosyal sorumluluk boyutlarının hiç birinin iş doyumu üzerinde etkili olmadığını belirlemiştir.

Diğer sektörlerde kurumsal sosyal sorumluluğun işgören doyumu üzerine etkilerinin çalışılmasına rağmen, turizm işletmelerindeki durumuna yönelik çalışma sayısı oldukça azdır. Lee ve diğerlerinin (2011) Seul'de zincir yiyecek-içecek işletmelerinde gerçekleştirdikleri çalışmada, KSS'nin yalnızca etik boyutunun iş doyumunu olumlu yönde etkilediğini belirlemişlerdir. Lee ve diğerlerinin (2012) Güney Kore'de kumarhanelerde yürüttükleri çalışmalarında, kurumsal sosyal sorumluluk faaliyetlerinin çalışanlarının örgütsel güven, iş doyumu ve müşteri odaklılığa etkileri araştırılmış, KSS'nin örgütsel güveni olumlu etkilediği, güvenin de iş doyumunu olumlu etkilediği belirlenmiştir. Çalışkan ve Ünüsan'ın (2011)Antalya'da otel işletmelerinde KSS'nin iş tatmini ve işte kalma niyeti üzerindeki etkilerini araştırdıkları çalışmalarında, işgörenlerin ekonomik, yasal, etik ve gönüllü sosyal sorumluluk algılamaları olumlu yönde bulunmuş, etik ve yasal sosyal sorumluluk boyutlarının iş tatmini ve işte kalma niyeti üzerinde anlamlı düzeyde et- 
kisi tespit edilmiştir. Valentine ve Fleischman (2008) çalışmalarında iş doyumu ile sosyal sorumluluk ilişkisinin araştırılmasını, Lee ve diğerleri (2011) defast-food işletmelerinde inceledikleri bu ilişkinin diğer hizmet işletmelerinde de sınanmasını önermektedir. Yazın taramasından elde edilen verilerle çalışmanın hipotezleri aşağıda sunulduğu gibi oluşturulmuştur.

$\mathrm{H}_{1}$ : Kurumsal sosyal sorumluluğun etik sosyal sorumluluk boyutu iş doyumunu olumlu yönde etkilemektedir.

$\mathrm{H}_{2}$ : Kurumsal sosyal sorumluluğun gönüllülük sosyal sorumluluk boyutu iş doyumunu olumlu yönde etkilemektedir.

$\mathrm{H}_{3}$ : Kurumsal sosyal sorumluluğun ekonomik sosyal sorumluluk boyutu iş doyumunu olumlu yönde etkilemektedir.

$\mathrm{H}_{4}$ : Kurumsal sosyal sorumluluğun yasal sosyal sorumluluk boyutu iş doyumunu olumlu yönde etkilemektedir.

\section{ARAŞTIRMA YÖNTEMI}

\subsection{Araştırma Deseni}

Çalışmada kantitatif yaklaşım benimsenmiş, alan araştırması yöntemi kullanılmıştır. Alan araştırmasında anket tekniği uygulanmıştır. Anketin yapılandırılması aşamasında ön araştırma yapılmıştır. Öncelikle yazın taramasından elde edilen bilgiler değerlendirilmiş ve ampirik çalışmalarda kullanılan ölçekler incelenerek soru listesi oluşturulmuştur. Daha sonra, oluşturulan ifadeler, anlaşılır ve sektöre uyumlu olması için, üç akademisyen ve iki profesyonel yönetici olmak üzere beş uzman tarafından gözden geçirilmiştir. Böylelikle içerik geçerliliği sağlanmıştır. Verilerin toplanması için konaklama işletmelerinden gerekli izinler alınmıştır. Araştırmada elde edilen veriler SPSS 16.0 (Statistical Program for Social Sciencies) programı ile analiz edilmiştir. Ölçeğin faktör yapı geçerliliği faktör analizi yapılarak gerçekleştirilmiştir. Daha sonra verilerin güvenirliği Cronbach's Alpha ile test edilmiştir. Ayrıca değişkenler arasındaki ilişki doğrusal regresyon analizi kullanılarak sınanmıştır.

\subsection{Veri Toplama Formu}

Veri toplama formu üç bölümden oluşmaktadır. İlk bölümde, kurumsal sosyal sorumluluk algısının ölçümünde, Carroll'un(1979) teorisine dayanan, Maignen ve Ferrell (2001) tarafından geliştirilen ve birçok çalışmada (Özdemir, 2007; Lee vd., 2009; Çalışkan ve Ünüsan, 2011; Lee vd., 2011) kullanılan ölçekten yararlanılarak hazırlanmış olan ölçek kullanılmıştır. Kurumsal sosyal sorumluluğun ekonomik, yasal, etik ve gönüllükten oluşan dört boyutuna ilişkin algılamaları 22 ifade ile değerlendirmektedir. Katılımcıların ifadelere katılımları ölçeğin orijinalinde (Maignen ve Ferrell, 2001) olduğu gibi beşli tutum ölçeği ile ("Kesinlikle Katılmıyorum" ile "Kesinlikle Katılıyorum") ölçülmüştür. Anketin ikinci bölümünde, iş doyumunu ölçmede, Hackman ve Oldham'ın (1975) "Iş Tanımlama Ölçeği'nden" derlenerek hazırlanan ölçek kullanılmıştır. Ölçek ücret, iş güvenliği, sosyal etkileşim, gelişim fırsatları ve denetim olmak üzere beş boyuttan oluşmaktadır.Anketin üçüncü bölümünde ise demografik sorulara yer verilmiştir.

Ölçeklerin İngilizceden Türkçeye tercümesi geri çeviri (back translation) tekniği uygulanarak yapılmıştır. Geçerliliği ve güvenilirliği önceden kanıtlanmış olan ölçek, ülkemiz bireyleri açısından nasıl algılandığını görmek için Çeşme'de bulunun 4 yıldızlı bir otelin çalışanlarından elde edilen 30 anketle pilot test uygulanmıştır. Pilot çalışmadan elde edilen iç tutarlılık değerleri (KSS ölçeğinin güvenirlik katsayısı 0,720, ile iş̧ doyumu ölçeğinin güvenilirlik katsayısı 0,712) kabul edilebilir sınırlar içinde oluşmuştur.

\section{3.Örneklem}

Araştırmanın evrenini, Çeşme'de faaliyet gösteren konaklama işletmeleri çalışanları oluşturmaktadır. Çeşme'nin alan olarak seçilmesinin nedeni; küçük bir alan olmasına karşın zincir ve grup otellerin bulunmasıdır. Çeşme'de faaliyet gösteren konaklama işletmeleri, Türkiye'deki diğer turizm bölgelerinden sunduğu hizmet bakımından farklılık göstermemektedir. Bu yönüyle de ana kitleyi temsil edebilmektedir. Kurumsal sosyal sorumluluk faaliyetlerinin daha çok büyük ölçekli ve kurumsal konaklama işletmelerinde uygulanmasından (Garay ve Font, 2012) dolayı çalışmaya dâhil edilen konaklama işletmeleri seçilmiştir. Veriler dört ve beş yıldızlı oteller, butik oteller ile birinci sınıf tatil köylerinden oluşan 7 konaklama işletmesi çalışanlarından iki haftalık süre içinde yüz-yüze toplanmıştır. Belirlenen konaklama işletmelerinde toplam 500 işgören olduğu belirlenmiş, çalışma yapıldığı süre içinde işletmede bulunan ve soruları cevaplamaya istekli olan çalışanlardan toplanan veri sayısı 229'dur. 
Tablo1: Katılımcıların Demografik Özellikleri Tablosu

\begin{tabular}{|c|c|c|c|c|c|}
\hline & $\begin{array}{l}\text { Sayı } \\
\text { (N) }\end{array}$ & $\begin{array}{c}\text { Yüzde } \\
(\%)\end{array}$ & & Sayı (N) & $\begin{array}{c}\text { Yüzde } \\
(\%)\end{array}$ \\
\hline \multicolumn{3}{|c|}{ YAŞ } & \multicolumn{3}{|c|}{ MESLEKTE ÇALIŞMA YILI } \\
\hline 20 ve altı & 22 & 9,6 & 1 yıldan az & 16 & 7,0 \\
\hline $21-30$ & 103 & 45,0 & $1-3 \mathrm{yll}$ & 61 & 26,6 \\
\hline $31-40$ & 71 & 31,0 & $4-6 \mathrm{yll}$ & 65 & 28,4 \\
\hline $41-50$ & 20 & 8,7 & 7-9 yıl & 43 & 18,8 \\
\hline 51 ve üstü & 13 & 5,7 & 10 yıldan fazla & 44 & 19,2 \\
\hline Toplam & 229 & 100,0 & Toplam & 229 & 100,0 \\
\hline \multicolumn{3}{|c|}{ EĞітіM } & \multicolumn{3}{|c|}{ OTEL } \\
\hline İlköğretim & 33 & 14,4 & 5 yıldızlı & 121 & 52,8 \\
\hline Lise & 133 & 58,1 & 4 yıldızlı & 57 & 24,9 \\
\hline Üniversite & 60 & 26,2 & Tatil köyü & 21 & 9,2 \\
\hline Lisansüstü & 3 & 1,3 & Butik otel & 30 & 13,1 \\
\hline Toplam & 229 & 100,0 & Toplam & 229 & 100,0 \\
\hline \multicolumn{3}{|c|}{ GÖREV } & \multicolumn{3}{|c|}{ CINSIYYT } \\
\hline FB & 87 & 38,0 & Kadın & 75 & 32,8 \\
\hline FO & 28 & 12,2 & Erkek & 154 & 67,2 \\
\hline HK & 61 & 26,6 & Toplam & 229 & 100,0 \\
\hline OFS & 22 & 9,6 & \multicolumn{3}{|c|}{ MEDENI DURUM } \\
\hline DB & 31 & 13,5 & Evli & 102 & 44,5 \\
\hline Toplam & 229 & 100,0 & Bekâr & 127 & 55,5 \\
\hline & & & Toplam & 229 & 100,0 \\
\hline
\end{tabular}

\section{BULGULAR}

\subsection{Demografik Dağılım}

Çalışmaya katılan bireylerin profili Tablo 1'de verilmiştir. Tablo 1 incelendiğinde, çalışmaya katılanların \%45'i 21-30 yaş arasında, \%31'inin de 31-40 yaş aralığında olduğu görülmektedir. Çalışmaya katılanların \%67'sinin ise erkeklerden oluştuğu belirlenmiş̧ir. Katılanların \%44'ünü evliler oluşturmuştur. Çalışmaya katılan bireylerin \%58,1 i lise, \%25,8 üniversite olmak üzere çalışanlarının çoğunun lise ve üniversite eğitimine sahip olduğu gözlenmiştir. Meslekte çalışma süresi incelendiğinde, \%26'sının 1-3 yıl arası, \%28,4'ü 4-6 yıl, \%18'inin 7-9 yıl süresince, \%19,4'ününde 10 yıldan fazladır turizm sektöründe çalıştığı görülmektedir.

\subsection{Güvenilirlik ve Geçerlik}

Araştırmada kullanılan KSS ölçeğinin güvenirlik katsayısı (Cronbach's Alpha) 0,898 ile İş doyumu ölçeğinin güvenilirlik katsayısı (Cronbach's Alpha) 0,882 bulunmuştur. Bu değerler, sosyal bilimler araştırmaları için kabul edilen alfa değeri olan 0,80 düzeyinde gerçekleştiğinden, araştırmada kullanılan ölçeklerin oldukça güvenilir olduğu söylenebilir (Nunnally, 1967:248). Çalışmada ölçeklerin yapı geçerliliği açıklayıcı faktör analizleri (AFA) ile gerçekleştirilmiştir. Daha anlamlı ve yorumlanabilir bir sonuç elde etmek için, düşük yüklü ya da aynı anda birden fazla faktöre yük veren (Hair vd., 2006) beş ifadenin silinmesi gerekmiştir.Veri setinin faktör analizi için uygunluğunun değerlendirilmesinde Barlett's Testi (Barlett's Test of Sphericity) ve Kaiser-Meyer-Olkin (KMO) Örneklem Yeterliliği Ölçütü kullanılmaktadır. Kurumsal sosyal sorumluluk ölçeğinde yapılan faktör analizi sonucunda Bartlett's Testi sonucu 1.515 ve $p$ anlamlılık değeri 0,000 olarak gerçekleşmiştir ki bu değer değişkenler arasında yüksek korelasyon değerleri olduğunu ifade etmektedir. Kaiser-Meyer- Olkin (KMO) örneklem değeri 0,909'dür. Bu değer ise faktör analizi uygulamak için yeterli düzeyde gerçekleşmiştir (Kalaycl, 2008). Faktör yapısını belirlemek ve anlamlı yorumlanabilir faktörler elde etmek amacı ile temel bileşenler analizi ve varimaks rotasyonu teknikleri kullanılmış, özdeğer istatistiği 1 'den büyük olan ve faktör yükü 0,30 'un üzerinde olan veriler dikkate alınmıştır. Verilere ilişkin faktör analizi sonuçları Tablo 2'de sunulmuştur. Kurumsal sosyal sorumluluğa yönelik faktör analizi tablosu incelendiğinde, verilerin üç boyutta toplandığı görülmektedir. Faktör analizinde "yasal sosyal sorumluluk" boyutu çıkmamıştır, bu nedenle $\mathrm{H}_{4}$ hipotezi kabul edilmemiştir. 
Tablo2: Kurumsal Sosyal Sorumluluk Değişkenine Yönelik Faktör Analizi Tablosu

\begin{tabular}{|c|c|c|c|c|c|c|c|}
\hline & $\begin{array}{l}\text { Faktör } \\
\text { Yükü }\end{array}$ & Özdeğer & Ortalama & $\begin{array}{l}\text { Açılanan } \\
\text { Varyans \% }\end{array}$ & $\mathrm{F}$ & a & $\mathrm{p}$ \\
\hline FAKTÖR 1: ETIK SOSYAL SORUMLULUK & & 6,54 & 3,743 & 20,154 & 7,62 & 0,84 & 0,00 \\
\hline $\begin{array}{l}\text { Bu kurum, ürün ve hizmetleri hakkında müşterilere } \\
\text { tam ve doğru bilgi sunmaktadır. }\end{array}$ & 0,708 & & & & & & \\
\hline $\begin{array}{l}\text { Bu kurum, çalışanların sağlık, güvenlik ve refahını } \\
\text { koruyan uygun düzenlemelere sahiptir. }\end{array}$ & 0,701 & & & & & & \\
\hline $\begin{array}{l}\text { Bu kurum, çalışanların yaşam kalitesini artıran sosyal } \\
\text { haklar (ulaşım, yemek, spor vb.) sağlamaktadır. }\end{array}$ & 0,667 & & & & & & \\
\hline $\begin{array}{l}\text { Bu kurum, tüketici hakları konusunda yasal } \\
\text { düzenlemelerin ötesinde bir duyarlıı̆a sahiptir. }\end{array}$ & 0,63 & & & & & & \\
\hline $\begin{array}{l}\text { Bu kurum, kanunlara uygun bir şekilde faaliyetlerini } \\
\text { gerçekleştirmektedir. }\end{array}$ & 0,604 & & & & & & \\
\hline $\begin{array}{l}\text { Bu kurum, müşteri memnuniyetine büyük önem } \\
\text { verir. }\end{array}$ & 0,585 & & & & & & \\
\hline $\begin{array}{l}\text { Bu kurum, rekabeti düzenleyen kanunlara } \\
\text { uymaktadır. }\end{array}$ & 0,509 & & & & & & \\
\hline FAKTÖR 2: GÖNÜLLÜ SOSYAL SORUMLULUK & & 1,801 & 3,665 & 18,488 & 9,54 & 0,79 & 0,00 \\
\hline $\begin{array}{l}\text { Bu kurum, eğitim, sağlık, kültür, sanat gibi faaliyetlere } \\
\text { destek olmaktadır. }\end{array}$ & 0,795 & & & & & & \\
\hline $\begin{array}{l}\text { Bu kurum, hayırsever kuruluşlara yardımda } \\
\text { bulunmaktadır. }\end{array}$ & 0,733 & & & & & & \\
\hline $\begin{array}{l}\text { Bu kurum, çalışanlarının gönüllü olarak katıldıkları } \\
\text { faaliyetleri desteklemektedir. }\end{array}$ & 0,711 & & & & & & \\
\hline $\begin{array}{l}\text { Bu kurum, toplumun sosyal sorunlarının çözümüne } \\
\text { yönelik çaba göstermektedir }\end{array}$ & 0,706 & & & & & & \\
\hline $\begin{array}{l}\text { Bu kurum, doğal çevreyi korumaya ve geliştirmeye } \\
\text { dönük faaliyetlere aktif olarak katılmaktadır. }\end{array}$ & 0,612 & & & & & & \\
\hline FAKTÖR3:EKONOMIK SOSYAL SORUMLULUK & & 1,165 & 3,468 & 17,281 & 2,9 & 0,82 & 0,02 \\
\hline $\begin{array}{l}\text { Bu kurum, faaliyet giderlerini düşürmek için } \\
\text { çabalamaktadır. }\end{array}$ & 0,761 & & & & & & \\
\hline $\begin{array}{l}\text { Bu kurum, müşterilerinin memnuniyetini } \\
\text { sağlamaktadır. }\end{array}$ & 0,711 & & & & & & \\
\hline $\begin{array}{l}\text { Bu kurum, gelirlerini en yüksek seviyeye çıkarmakta } \\
\text { başarılıdır. }\end{array}$ & 0,694 & & & & & & \\
\hline $\begin{array}{l}\text { Bu kurum, çalışanların verimli çalışmasını } \\
\text { sağlamaktadır. }\end{array}$ & 0,666 & & & & & & \\
\hline $\begin{array}{l}\text { Bu kurum, rakiplerine göre rekabet avantajına } \\
\text { sahiptir. }\end{array}$ & 0,618 & & & & & & \\
\hline
\end{tabular}

(Not: Kaiser-Meyer-Olkin Örneklem Ölçümü =0,909; Bartlett's Test of Sphericity =1.515; Toplam Farkın (Varyans) Açıklama Oranı: 55,923)

Birinci faktör, "etik sosyal sorumluluk" olarak adlandırılmıştır. Etik sosyal sorumluluğun özdeğeri 6,540 ve toplam varyansın \%20,154'ünü açıklamaktadır. Etik Birinci faktör, "etik sosyal sorumluluk" olarak adlandırılmıştır. Etik sosyal sosyal sorumluluğa katılımcılar ortalama değer olarak 3,743 vermişlerdir. Faktör analizi sonucunda elde edilen ikinci faktör, "gönüllü sosyal sorumluluk" olarak adlandırılmıştır. İkinci faktörün özdeğeri, 1,801'dir ve toplam varyansın \%18,488'ini açıklamaktadır. Katılımcılar bu faktöre ortalama olarak 3,665 vermişlerdir Üçüncü faktör ise "ekonomik sosyal sorumluluk" olarak adlandırılmıştır. Üçüncü faktörün özdeğeri, 1,165'dir ve toplam varyansın \%17,281'ini açıklamaktadır. Bu faktöre katılımcılar, ortalama değer olarak 3,468 vermişlerdir. 
Tablo 3: İş Doyumu Değişkenine Yönelik Faktör Analizi Tablosu

\begin{tabular}{|l|l|l|l|l|l|l|l|}
\hline & $\begin{array}{c}\text { Faktör } \\
\text { Yükü }\end{array}$ & Özdeğer & Ortalama & $\begin{array}{c}\text { Açıklanan } \\
\text { Varyans \% }\end{array}$ & $\mathrm{F}$ & $\alpha$ & $\mathrm{p}$ \\
\hline FAKTÖR 1: I̧̧ DOYUMU & & 3,918 & 3,537 & 48,979 & 7,855 & 0,863 & 0,000 \\
\hline $\begin{array}{l}\text { İ̧̧ arkadaşlarımla yaratılan kaynaşma ortamından } \\
\text { memnunum. }\end{array}$ & 0,812 & & & & & & \\
\hline İşyerindeki yardımlaşma ortamından memnunum. & 0,792 & & & & & & \\
\hline $\begin{array}{l}\text { İş yaparken kazandığım kişisel gelişimden } \\
\text { memnunum. }\end{array}$ & 0,778 & & & & & & \\
\hline İşte birlikte çalıştığım insanlardan memnunum. & 0,778 & & & & & \\
\hline $\begin{array}{l}\text { Yaptığım işten dolayı kendimi yararlı ve başarılı his- } \\
\text { sederim. }\end{array}$ & 0,761 & & & & & & \\
\hline Sahip olduğum iş güvencesinden memnunum. & 0,647 & & & & & \\
\hline $\begin{array}{l}\text { Yöneticiden gördüğüm saygılı ve eşit muamelenin } \\
\text { derecesinden memnunum. }\end{array}$ & 0,534 & & & & & \\
\hline Aldığım ücret ve yan ödemelerden memnunum. & 0,371 & & & & & \\
\hline
\end{tabular}

(Not:Kaiser-Meyer-Olkin Örneklem Ölçümü =0,863; Bartlett's Test of Sphericity =673,976; Toplam Farkın (Varyans) Açıklama Oranı: 48,979)

İ̧ doyumu ölçeğinde yapılan faktör analizi sonucunda Bartlett's Testi sonucu 673,976 ve $p$ anlamlılık değeri 0,000 olarak gerçekleşmiştir ki bu değer değişkenler arasında yüksek korelasyon olduğunu ifade etmektedir. Kaiser-Meyer-Olkin (KMO) örneklem değeri 0,909'dür. Bu değer ise faktör analizi uygulamak için yeterlidir (Kalaycı, 2008). Verilere ilişkin faktör analizi sonuçları Tablo 3'de sunulmuştur. Iş duyumuna yönelik faktör analizi tablosu incelendiğinde, verilerin tek boyutta toplandığı görülmektedir. İş doyumunun özdeğeri 3,918ve toplam varyansın \%48,979'unu açıklamaktadır. İş doyumuna katılımcılar ortalama değer olarak 3,537 vermişlerdir.

\subsection{Regresyon Analizi}

KSS'nin iş doyumu üzerindeki etkisini görmek için doğrusal regresyon analizi uygulanmıştır. KSS'nin üç boyutu ile iş doyumu arasında regresyon analizi sonuçları Tablo 4'de görülmektedir. Çok değişkenli korelasyon katsayısı 0,288, belirlilik katsayısı 0,545 olarak bulunmuştur. Anova testine göre $p=0,01 \leq a=0,05$ olduğundan anlamlıdır. KSS boyutlarının, iş doyumunu açıklama oranı $\% 28,8^{\prime}$ dir (Düzeltilmiş $\mathrm{R}^{2}=0,288$ ). Analiz sonucunda KSS'nin iki boyutunun iş doyumunu olumlu yönde etkilediği görülmektedir. İş doyumu üzerinde etkili olan birinci boyut etik sosyal sorumluluk boyutudur $(\beta=0,359 ; t=5,036 ; p=0,000)$. Etik sosyal sorumluluk boyutunun iş doyumunu olumlu yönde etkilediği görülmektedir. Böylece çalışmanın $\mathrm{H}_{1}$ hipotezi kabul edilmiştir. İş doyumu üzerinde etkili olan ikinci boyut ise ekonomik sosyal sorumluluk bo- yutudur ( $\beta=0,80 ; t=2,699 ; P=0,007)$. Ekonomik sosyal sorumluluk boyutunun da iş doyumunu olumlu yönde etkilediği belirlenmiştir. Böylece çalışmanın $\mathrm{H}_{3}$ hipotezi de kabul edilmiştir.

Tablo 4: KSS Boyutları ile İş Doyumu Regresyon Analizi Tablosu

\begin{tabular}{|l|c|c|c|}
\hline \multirow{2}{*}{ Bağımsız Değişkenler } & Beta & $\mathrm{t}$ & Sig \\
\cline { 2 - 4 } & & 3,462 & 0,001 \\
\hline Etik Sosyal Sorumluluk & 0,359 & 5,036 & 0,000 \\
\hline Ekonomik Sosyal Sorumluluk & 0,180 & 2,699 & 0,007 \\
\hline Gönüllü Sosyal Sorumluluk & 0,112 & 1,722 & 0,086 \\
\hline
\end{tabular}

(Not: Multiple $\mathrm{R}=0,545 ; \mathrm{R}^{2}=0,297$; Düzeltilmiş $\mathrm{R}^{2}=0,288$; $\mathrm{F}=31,699$; Sig. =0,000 Bağımlı Değişken: İş Doyumu)

Çalışanların kurumsal sosyal sorumluluk algılamalarının iş duyumuna etkisini belirlemek amacıyla gerçekleştirilen regresyon analizi sonuçlarına göre; etik ve gönüllü sosyal sorumluluk boyutları,iş doyumunu anlamlı ve olumlu yöndeetkilediği ortaya çıkmaktadır. Etik sosyal sorumluluk boyutunun iş doyumu üzerindeki etkisi ekonomik sosyal sorumluluktan daha fazladır. Gönüllülük sosyal sorumluluk boyutu ile iş doyumu arasında istatistiki olarak anlamlı bir sonuç bulunmamıştır. Böylece çalışmanın $\mathrm{H}_{2}$ hipotezi kabul edilmemiştir. 


\section{TARTIŞMA VE SONUÇ}

Bu çalışmada konaklama işletmelerindekurumsal sosyal sorumluluk ile iş doyumu arasındaki ilişki belirlenmeye çalışılmıştır. Çalışmanın amacını gerçekleştirebilmek için gerekli olan veriler Çeşme'de faaliyet gösteren 5 ve 4 yıldızlı oteller ile tatilköyleri ve butik otellerden toplanmıştır. Toplanan veriler analiz edildiğinde, kurumsal sosyal sorumluluğun etik sosyal sorumluluk, gönüllü sosyal sorumluluk ve ekonomik sosyal sorumluluk olmak üzere üç boyut altında, iş doyumunun ise tek boyut altında toplandığı görülmüştür. Carroll'un (1979) sınıflandırma teorisine dayanan Türkiye'de yapılmış çalışmalara göz atıldığında; Çalışkan ve Ünüsan (2011) ile Özdemir'in (2007) çalışmalarında KSS dört boyut altında toplanırken, Akdoğan ve Bay'ın (2012) çalışmalarında ise beş boyut altında toplanmıştır. Akdoğan ve Bay'ın (2012) çalışmalarında diğer çalışmalardan farklı olarak beşinci boyut, toplumsal KKS bileşenidir. Bu çalışmada Carroll'un teorisinde bulunan yasal sosyal sorumluluk boyutu ayrı bir boyut olarak çıkmamıştır. Uygulama alanı olarak farklı sektörler ve bölgelerin seçimi sonuçlarda etkili olabilir.Çalışmada, etik sosyal sorumluluk boyutu ile yasal sosyal sorumluluk boyutunun tek boyut altında birleştiğini görmekteyiz. Ölçekte yer alan yasal sosyal sorumluluğu ölçen ifadelerin etik sosyal sorumluluk boyutu altında toplandığı görülmüştür. Katılımcıların, kurumun etik davranışları ile yasalara uymasını ayrı algılamadığı sonucuna varabiliriz.Çeşme'de yer alan konaklama işletmelerinin genelde zincir işletmeler ve kurumsallaşmış işletmeler olmasıyla, işgörenlerinin algısında, yasal yükümlülükleri ile birlikte etik sorumluluklarını da yerine getirdikleri sonucu çıkarılabilir.

Çalışmada kurumsal sosyal sorumlulukta birinci boyut etik sosyal sorumluluk, ikinci boyut gönüllülük sosyal sorumluluk ve üçüncü boyut da ekonomik sosyal sorumluluk boyutu olarak ortaya çıkmıştır. Çalışkan ve Ünüsan'ın (2011) KSS boyutlarının algılanması ortalamaları itibariyle en yüksekten en düşüğe ekonomik, yasal, etik ve gönüllülük boyutu şeklinde sıralanırken, Özdemir'in (2007) çalışmasında bu sıralama yasal, etik, ekonomik ve gönüllülük boyutu şeklindedir.Lee ve diğerlerinin (2011) çalışmasında ise sırasıyla etik, gönüllülük, yasal ve ekonomik sosyal sorumluluk boyutları olarak bulunmuştur. Bu çalışma ile karşılaştırıldığında, yasal boyutun bulunmamasıyla birlikte, Lee ve diğerlerinin (2011) zincir fast-food işletmeleri işgörenleri üzerinde gerçekleştirdikleri çalışmayla, boyutların sıralaması aynı çıkmıştır.

Kurumsal sosyal sorumluluğun iş doyumuna etkisini görebilmek için regresyon analizi yapılmıştır. Regresyon analizi sonuçlarına göre, KSS'nin etik ve ekonomik sosyal sorumluluk boyutları iş doyumunuolumlu yönde etkilemektedir.Etik sosyal sorumluluk boyutu- nun iş doyumu üzerindeki etkisi ekonomik sosyal sorumluluktan daha fazladır. Lee ve diğerleri (2011) ile Valentine ve Fleishman'ın (2008) çalışmaları KSS'nin yalnızca etik boyutununiş doyumunu olumlu yönde etkilediğini göstermiştir.Çalışkan ve Ünüsan'ın (2011) çalışmalarında iş doyumu üzerinde etkili olan KSS boyutlarının etik ve yasal sosyal sorumluluklar olduğunu belirlemişlerdir.Analizde gönüllülük sosyal sorumluluk boyutunun iş doyumu üzerinde etkisi tespit edilememiştir. Daha önceki çalışmalarda da bu yönde bir bulguya ulaşılamamışır. Buradan hareketle, işletmelerin gönüllü sosyal sorumluluk uygulamalarının işgörenlerin doyumu üzerinde etkisinin olmadığı söylenebilir. İşgörenler, işletmelerin gönüllü faaliyetlere ayırdıkları fonları işgörenlere harcamalarını istiyor olabilirler.

Konaklama işletmeleri, iş doyumunu artırmak için etik ve ekonomik sosyal sorumluluklarını artırmalıdır. Etik sosyal sorumluluk boyutu diğer boyutlara göre daha fazla iş ortamı ve örgüt iklimi ile ilişkilidir (Lee vd., 2011). Işsletmelerin etik politikası doğrudan iş ortamını etkilemektedir.Konaklama işletmelerinin işgörenlerine ve müşterilerine karşı etik tutumları işgörenlerin doyumunda önemlidir (Pettijohn vd., 2008). Çalışanlara haklarını vermek, yasalara uymak, yaşam kalitesine katkıda bulunmak, müşterileri doğru bilgilendirmek etik sorumluluklar içinde yer almaktadır.Daha önce yapılan çalışmalardan farklı olarak bu çalışmada ekonomik kurumsal sosyal sorumluluğun da iş doyumunu etkilediğini görmekteyiz. Ekonomik KSS boyutunu ölçen sorular, işletmenin ekonomik başarısına yönelik ifadelerden oluşmaktadır. Müşteri memnuniyetini sağlama, işgörenlerin verimini artırma ve rekabet avantajına sahip olma gibi ifadeler iş doyumunda da etkili başarı faktörünü (Yang, 2010) öne çıkarmaktadır. Otel işletmelerinin ekonomik kurumsal sosyal sorumluluk faaliyetlerini artırmaları, işgörenlerinin iş doyumunu da arttıracağı söylenebilir. KSS uygulamalarının işletmenin imajı, müşteri memnuniyetinin yanında işgörenler üzerinde de olumlu etkili olduğu bu çalışma ile de desteklenmiştir. Çalışmanın sonuçlarından hareketle, konaklama işletmelerinin kurumsal sosyal sorumluluklarını yerine getirmenin dış paydaşlara sağladığı yararlarının yanında işgörenlerin doyumu üzerindeki olumlu etkisi nedeniyle önemli bir görev olduğu değerlendirmesi yapılabilir.

Çalışmanın en önemli kısıtıgeniş bir alanda yapılamamış olmasıdır. Çalışmanın tüm ülke çapında yapılması daha genellenebilir sonuçlar verecektir Ancak çalışma zaman ve erişim kısıtları nedeniyle Çeşme'de gerçekleştirilmiştir.lleride yapılacak çalışmalara, kurumsal sosyal sorumluluğun, işgörenlerin iş tutumlarının tümü ile ilişkisinin araştırılması ve kalitatif yöntemle desteklenmesi önerilebilir. 


\section{KAYNAKLAR}

Akdoğan, K.F. ve Bay, E. (2012)"İsteğe Bağlı Kurumsal Sosyal Sorumluluk Faaliyetleri: Görünürde Hayırseverlik" Amme Idaresi Dergisi, 45(1):51-75.

Alakavuklar, O.N., Kılıçaslan, S. ve Öztürk, E.B. (2009)“Türkiye'de Hayırseverlikten Kurumsal Sosyal Sorumluluğa Geçiş: Bir Kurumsal Değişim Öyküsü” Yönetim AraştırmalarıDergisi,9(2):103-143.

Ararat, M. (2008)“A Development Perspective for Corporate Social Responsibility: Case of Turkey" Corporate Governance, 8(3):271-285.

Arnett, D.B., Laverie, D.A. ve McLane, C. (2002)"Using Job Satisfaction and Pride as InternalMarketing Tools"Cornell Hotel and Restaurant Administration Quarterly, 43(2):87-96.

Bielak, D., Bonini, S.M.J. ve Oppenheim, J.M. (2007) "CEOs on Strategy and Social Issues. The McKinsey Quarterly, Web Exclusive, October”,http:// www.mckinseyquarterly.com/article_page.aspx?ar=2056 \&pagenum=7, (22/06/2012).

Berger, I.E., Cunningham, P.H. ve Drumwright, M.E. (2006)“Identity, Identification, and Relationship Through Social Alliances"Journal of the Academy of Marketing Science, 34(2): 128-137.

Bies, R.J., Bartunek, J.M., Fort, T.L. ve Zald, M.N. (2007) “Corporation as Social Chance Agents: Individual, Interpersonal, Institutional and Environmental Dynamics" Academy of Management Review, 32:788-793.

Boddy, C.R., Ladyshewsky, R.K. ve Galvin, P. (2010)“The Influence of Corporate Psychopaths on Corporate Social Responsibility and Organizational Commitment to Employees"Journal of Business Ethics, 97:1-19.

Bonache, J. (2005)"Job Satisfaction Among Expatriates, Repatriates and Domestic Employees: The Perceived Impact of International Assignments on Workrelated Variables" Personnel Review, 34(1):110-124.

Bowen, H.R. (1953)Social Responsibilities of Businessman, New York, Harper\&Row.

Brammer, S. ve Millington, A. (2005)“Corporate Reputation andPphilanthropy: An Empirical Analysis"Journal of Business Ethics, 61:29-44.

Brammer, S., Millington, A. ve Rayton, B. (2007)“The Contribution of Corporate Social Responsibility to Organizational Commitment"International Journal of Human Resource Management,18(10):1701-1719.

Brown, T.J. ve Dacin, A.P.(1997)“The Company and the Product: Corporate Associations and Consumer Product Responses"Journal of Marketing, 61:68-84.
Carroll, A.B. (1979)“A Three Dimensional Conceptual Model of Corporate Social Performance"Academy of Management of Review, 4(4):497-505.

Carroll, A.B. (1991)“The Pyramid of Corporate Social Responsibility:Toward the Moral Management of Organizational Stakeholders"Business Horizons, 4:39-48.

Claydon,T.veDoyle, M. (1996)“Trusting Me, Trusting You? The Ethics of Employee Empowerment" Personnel Review,25(6):13-25.

Collier, J. ve Esteban, R. (2007)“Corporate Social Responsibility and Employee Commitment"Business Ethics: A European Revie. 16(1):19-33.

Çalışkan, O. ve Ünüsan, Ç. (2011)“Otel Çalışanlarının Kurumsal Sosyal Sorumluluk Algısının İş Tatmini ve İşte Kalma Niyetine Etkisi" Anatolia: Turizm Araştırmaları Dergisi,22(2):154-166.

Ertuna, B. ve Tükel, A. (2009)“Türkiye’de KSS Uygulamaları: Geleneksel ve Küresel Arasında"Yönetim Araştırmaları Dergisi, 9(2):145-172.

Font, X., Walmsley, A., Cogotti, S., McCombes, L. ve Häusler, N. (2012) "Corporate Social Responsibility: The Disclosure-Performance Gap” Tourism Management, 33:1544-1553.

Garay, L. ve Font, X. (2012) "Doing Good to Do Well? Corporate Social Responsibility Reasons, Practices and Impacts in Small and Medium Accommodation Enterprises"International Journal of Hospitality Management, 31:329-337.

Gil, I., Berenguer, G.ve Cervera, A. (2008)"The Roles of Service Encounters, Service Value, and Job Satisfaction in Achieving Customer Satisfaction in Business Relationships" Industrial Marketing Management, 37:921-939.

Golja, T. ve Nižić, M.K. (2010)“Corporate Social Responsibility in Tourism-The Most Popular Tourism Destinations in Croatia: Comparative Analysis" Managem ent, 15(2):107-121.

Grosbois, D. (2012)“Corporate Social Responsibility Reporting by the Global Hotel Industry: Commitment, Initiatives and Performance"International Journal of Hospitality Manageme, 31:896-905.

Hair, J.F., Anderson, R.E., Tatham, R.L., ve Black, W. (2006). Multivariate Data Analysis. Prentice Hall. 6. Baskı. New Jersey.

Hansen, S.D., Dunford. B.B., Boss, A.D., Boss, W.R. ve Angermeier, I. (2011)“Corporate Social Responsibility and the Benefits of Employee Trust: A Cross-Disciplinary Perspective"J Bus Ethics, 102:29-45. 
Henderson, J.C. (2007)“Corporate Social Responsibility and Tourism: Hotel Companies in Phuket, Thailand, After the Indian Ocean Tsunami"Hospitality Management, 26:228-239.

Homburg, C. ve Stock, R.M. (2004)“The Link Between Salespeople's Job Satisfaction and Customer Satisfaction in a Business-to-Business Context: a Dyadic Analysis"Journal of Academy of Marketing Science, 32(2):144-158.

Inoue, Y. ve Lee,S.(2011)"Effects of Different Dimensions of Corporate Social Responsibility on Corporate Financial Performance in Tourism-Related Industries" Tourism Management,32:790-804.

Judge, T.A., Thoresen, C.J., Bono, J.E., ve Patton, G.K. (2001)“The Job Satisfaction-job Performance Relationship: A Qualitative and Quantitative Review"Psychological Bullet, 127:376-407.

Kalayc1, Ş. (2008)SPSS Uygulamalı Çok Değişkenli İstatistik Teknikleri, 3.Baskı, Ankara, Asil Yayın Dağıtım Ltd. Şti.

Kang, K.H., Lee, S. ve Huh, C. (2010)"Impacts of Positive and Negative Corporate Social Responsibility Activities on Company Performance in the Hospitality Industry" International Journal of Hospitality Management, 29:72-82.

Kemper, A., Martin, R.L. (2010) “After the Fall:The Global Financial Crisis as a Test of Corporate Social Responsibility Theories"European Management Review, $7(4): 229-240$.

Kim, E.E.K., Kang, J. ve Mattila A.S. (2012)“The Impact of Prevention Versus Promotion Hope on CSRActivities" International Journal of Hospitality Managemen. 31:43-51.

Küskü, F. ve Erçek, M. (2000) "Vatandaş Kuruluş Kavramı: Türk Kuruluşları İyi Birer Vatandaş mı?" Amme İdaresi Dergisi,33(3):79-95.

Küskü, F. ve Zarkada-Fraser, A. (2004)“An Empirical Investigation of Corporate Citizenship in Australia and Turkey" British Journal of Management, 15:57-72.

Lambert, E.G. Lynn, H.N. ve Barton, S.M.(2001)“The Impact of Job Satisfaction on Turnover Intent: A Test of a Structural Measurement Model Using a National Sample of Workers" The Social Science Journal, 38:233-250.

Larson, B.V., Flaherty, K.E.,Zablah,, A.R.,Brown T.J. ve Wiener, J.L. (2008)“Linking Cause-RelatedMarketing to Sales Force Responses and Performance in a Direct Selling Context" Journal of the Academy of Marketing Science, 36(2):271-277.

Lee, S. ve Heo, C.Y. (2009)“Corporate Social Responsibility and Customer Satisfaction Among US Publicly Traded Hotels and Restaurants"International Journal of Hospitality Management,28:635-637.
Lee, S. ve Park, S.Y. (2009)“Do Socially Responsible Activities Help Hotels and Casinos Achieve their Financial Goals?"International Journal of Hospitality Management, 105-112.

Lee, H., Park, T.K., Moon, H.K., Yang, Y.H. ve Kim, C. (2009)"Corporate Philanthropy, Attitude Towards Corporations, and Purchase Intentions: a South Korea Study" Journal of Business Research, 62(10):939-946.

Lee, Y.Ki, Kim,Y.S., Lee, K.H, ve Li, D. (2011)“The Impact of CSR on Relationship Quality and Relationship Outcomes: A Perspective of Service Employees"International Journal of Hospitality Management,31(3):745:756.

Lee, C-Ki., Song, H-J., Lee, H-Mi, Lee, S. ve Bernhard, B.J. (2012)"The Impact of CSR on Casino Employees' Organizational Trust, Job Satisfaction, and Customer Orientation: An Empirical Examination of Responsible Gambling Strategies"International Journal of Hospitality Management, Basımda.

Leiter, M.P., Harvie, P. ve Erizzell, C. (1998)“The Correspondence of Patient Satisfaction and Nurse Burnout"Social Sciences Medicine, 47(10):1611-1617.

Lis, B. (2012)"The Relevance of Corporate Social Responsibility for a Sustainable Human Resource Management: An Analysis of Organizational Attractiveness as a Determinant in Employees' Selection of a (Potential) Employer"Management Revu,23(3):279295.

Locke, E.A. (1976) The Nature and Causes of Job Satisfaction. In M. D. Dunnette (eds.) "Handbook of Industrial and Organizational Behavior" Chicago, Rand McNally.

Luo, X., ve Bhattacharya, C.B. (2006)“Corporate Social Responsibility, Customer Satisfaction, and Market Value" Journal of Marketing, 70:1-18.

Maignan, I. ve Ferrell, O.C. (1998)“Definition and Operatioanalization of Corporate Citizenship: A CrossCultural Approach" The American Marketing Association Marketing Exchange Colloquium.

Maignan, I. ve Ferrell, O.C. (2001)“Antecedents and Benefits of Corporate Citizenship: An Investigation of French Businesses" Journal of Business Research, 51:1-15.

Margolis, J.D. ve Walsh, J.P. (2003)"Misery Loves Companies: Whither Social Initiatives by Business?" Administrative Science Quarterley, 48(2):268305.

Martens, B.J. ve Arkidge, J.T. (2006)“Customer Relationship Management at Farm Credit Service of America: Working Toward a Single View"International Food and Agribusiness Management Review, 9(3):23-37. 
McWilliams, A. ve Siegel, D. (2001)"Corporate Social Responsibility: A Theory of the Firm Perspective" Academy of Management Review, 26:117-127.

Midttun, A. (2007)“Corporate Responsibility from a Resource and Knowledge Perspective. Towards a Dynamic Reinterpretation of C(S)R: are Corporate Responsibility and Innovation Compatible or Contradictory?" Corporate Governan, 7(4):401-413.

Mohr, L.A. ve Webb, D.J.(2005)“The Effects of Corporate Social Responsibility and Price on Consumer Responses"Journal of Consumer Affair, 39 (1):121-147.

Namasivayam, K. ve Zhao, X. (2007)“An Investigation of the Moderating Effects of Organizational Commitment on the Relationships Between Work-Family Conflict and Job Satisfaction Among Hospitality in India"Tourism Manageme, 28:1212-1223.

Nunnally, J.C. (1967)Psychometic Theory, New York, McGraw Hill.

Özdemir, H.Ö. (2007)“Çalışanların Kurumsal Sosyal Sorumluluk Algılamalarının Örgütsel Özdeşme, Örgütsel Bağlllık ve İş Tatminine Etkisi: Opet Çalışanlarına Yönelik Uygulama" Doktora Tezi, İstanbul, Marmara Üniversitesi Sosyal Bilimler Enstitüsü.

Özgener, Ş. (2004)İş Ahlakının Temelleri: Yönetsel Bir Yaklaşım, Nobel Yayınevi.

Pelit, E., Keleş, Y. ve Çakır, M. (2009) "Otel İşletmelerinde Sosyal Sorumluluk Uygulamalarının Belirlenmesine Yönelik Bir Araştırma”Yönetim ve Ekonomi, 16(2):18-30.

Pettijohn, C., Pettijohn, L., ve Taylor, A.J. (2008) "Salesperson Perceptions of Ethical Behaviors: Their Influence on Job Satisfaction and Turnover Intentions" Journal of Business Ethics, 78:47-557.

Rodrigo, P. ve Arenas, D. (2008)“Do Employees Care About CSR Programs? A Typology of Employees According to their Attitudes"Journal of Business Ethics, 83:265-283.

Rudež, H.N. (2010) “Integratıon of Corporate Social Responsibility into Loyalty" Tourism and Hospitality Management, 16(1):101-108.

Rupp, D.E., Ganapathi, J., Aguilera, R.V. ve Williams, C.A. (2006) “Employee Reactions to Corporate Ocial Responsibility: an Organizational Justice Framework"Journal of Organizational Behaviou, 27:537543.

Sekaran, U. ve Bougie, R. (2010)Research Metods for Business, John Wiley and Sons, Ltd.Uk.

Sen, S. ve Bhattacharya, C.B. (2001)"Does Doing Good Always Lead to Doing Better? Consumer Reactions to Corporate Social Responsibility" Journal of Marketing Resear, 38: 225-245.
Sloan, P., Legrand, W. ve Chen, J.S. (2009) Sustainability in the Hospitality Industry: Principles of Sustainable Operations, Elsevier Inc.

Spector, P.E. (1997)Satisfaction: Application, Assessment, Causes, and Consequences, CA, Sage Publications.

Tamm, K., Eamets, R.ve Mótsmees, P. (2010)"Relationship Between Corporate Social Responsibility and Job Satisfaction: The Case of Baltıc Countries'University of Tartu Faculty of Economics and Business Administration Working Paper Series.

Tepeci, M. (2005)“The Dimensions and Impacts of Organizational Culture on Employee Job Satisfaction and Intent to Remain in the Hospitality and Tourism Industry in Turkey"Journal of Travel and Tourism Research, 5(1/2):21-39.

Tett, R.P.ve Meyer, J.P. (1993)“Job Satisfaction, Organizational Commitment, Turnover Intention and Turnover: Path Analyses Based on Meta-Analytic Findings" Personnel Psycholog, 46(2):259-294.

Tripathy, S.K. ve Rath, N. (2011)"Practice of Corporate Social Responsibility in NALCO and the Perceptions of Employees and the Public: A Case Study" South Asian Journal of Management. 18(4):44-61.

Tsai, H., Tsang, N.K.F., ve Cheng, S.K.Y. (2012) "Hotel Employees' Perceptions on Corporate Social Responsibility: The Case of Hong Kong"International Journal of Hospitality Management,31(4):1143-1154.

Turker, D. (2009)“How Corporate Social Responsibility Influences Organizational Commitment"Journal of Business Ethic, 89:189-204.

Tuzzolino, F. ve Armandi, B.R. (1981)“A NeedHierarchy Framework for Assessing Corporate Social Responsibility" Academy of Management Review, 6(1):21-28.

Tütüncü, Ö. ve Çiçek, O. (2000)“İş Doyumunun Ölçülmesi: İzmir İl Sınırlarında Faaliyet Gösteren Seyahat Acenteleri Üzerine Bir İnceleme" Anatolia Turizm Arasttrmaları Dergisi, 11(3):124-128.

Valentine, S. ve Fleishman, G. (2008)"Ethics Programs, Perceived Corporate Social Responsibility and Job Satisfaction”Journal of Business Ethics, 77(2):159-172.

Vohra, N. ve Sheel (2012)"Corporate Social Responsibility:Practice, Theory, and Challenges"Vikalpa, 37(2):73-116.

Yamak, S. (2007) Kurumsal Sosyal Sorumluluk Kavramının Gelişimi, İstanbul, Beta Yayıncılık.

Yamak, S. (2009) "Kurumsal Sosyal Sorumluluk: Yerel Farklılıklar, Küresel Aynılıklar" Yönetim Araştırmaları Dergisi,9(2):95-101.

Yang, J.T. (2010)"Antecedents and Consequences of Job Satisfaction in the Hotel Industry" International Journal of Hospitality Management, 29:609-619. 
